\title{
DESEMPENHO AGRONÔMICO DE VARIEDADES DE MILHOS CRIOULOS CULTIVADOS NO VALE DO JEQUITINHONHA
}

Edelço Aparecida Saraiva ${ }^{1 *}$, Amanda Gonçalves Guimarães ${ }^{1}$, Josimar Rodrigues Oliveira ${ }^{1}$, Natália Oliveira Silva ${ }^{1}$, Leticia Lopes de Oliveira ${ }^{1}$, Andreza Aparecida Alves Campos ${ }^{1}$, Leandra Cardoso Moreira $^{1}$, Márcia Regina da Costa ${ }^{1}$

\begin{abstract}
RESUMO - A cultura do milho é uma das principais no cenário econômico agrícola brasileiro. Seu cultivo pode ser realizado por genótipos comerciais e locais, conforme o perfil de agricultura desenvolvido em cada região. Objetivou-se com este trabalho avaliar o desempenho agronômico e caracterizar por meio de alguns descritores, genótipos de milho crioulo, variedades melhoradas e comerciais para o cultivo em Couto de Magalhães de Minas-MG. O experimento foi conduzido na Fazenda Experimental Rio Manso, da UFVJM, durante a safra 2017/18. Foram estudadas seis variedades de milho crioulo, duas variedades melhoradas e duas variedades comerciais. As características avaliadas foram: tombamento, prolificidade, caracterização de espigas e grãos, bem como a produtividade de espigas e grãos. Os genótipos de milhos crioulos CR3, CR4 e CR6, oriundos de agricultores familiares locais que integram o Projeto Milho Crioulo, a variedade de população aberta Piranão e a variedade comercial UFVM 200 apresentaram produtividade de grãos satisfatória para a região.
\end{abstract}

Palavras chave: agricultura familiar, baixo nível tecnológico, variedades tradicionais, Zea mays L.

\section{AGRONOMIC PERFORMANCE OF CRIOLLO CORN VARIETIES CULTIVATED IN JEQUITINHONHA VALLEY}

\begin{abstract}
Maize is one of the main crops in the Brazilian agricultural economic scenario, in which its cultivation can be carried out by commercial and local genotypes. The objective of this work was to evaluate the agronomic performance and characterize by means of some descriptors, genotypes of creole maize, improved and commercial varieties for cultivation in Couto de Magalhães de Minas-MG. The experiment was conducted at the Rio Manso Experimental Farm, Universidade Federal dos Vales do Jequitinhonha e Mucuri, during the 2017/18 harvest. The genetic materials studied were six varieties of creole maize, two improved varieties and two commercial varieties. The evaluated characteristics were: tipping, prolificacy, characterization of spikes and grains and yield of spikes and grains. The genotypes of Creole maize, CR3, CR4 and CR6 originated from the project of multiplication and conservation of genotypes of Creole maize for family agriculture in the region of Couto de Magalhães de Minas, open pollinated varieties Piranão and commercial varieties UFVM 200 variety present satisfactory grain yield for the region.
\end{abstract}

Keywords: greenhouse gases, low carbon agriculture, Paris agreement.

\footnotetext{
${ }^{1}$ Universidade Federal dos Vales do Jequitinhonha e Mucuri, Departamento de Agronomia: amandagguimaraes@yahoo.com.br, josimarodrigues@yahoo.com.br, nataliasilva.13@hotmail.com,marciarcosta2003@yahoo.com.br,LeticiaLopeso@hotmail.com, andrezacampos04@yahoo.com,leandracmoreira@gmail.com

*Autor para correspondência: edelcosaraiva@gmail.com
} 


\section{INTRODUÇÃO}

O Brasil é o terceiro maior produtor de milho do mundo, atrás de China que foi responsável por 215 milhões de toneladas na safra 2017/2018 e os Estados Unidos que lideraram a produção chegando a 370 milhões de toneladas na safra 2017/2018 (Agência Brasil, 2018). A produção nacional de milho na safra 2017/18 foi de $80.709,60$ milhões de tonelada e esteve distribuída principalmente nos estados do Mato Grosso $(32,7 \%)$, Paraná (14,7\%), Goiás (10,1 \%), Minas Gerais (8,8 \%), Mato Grosso do Sul (8\%) e Rio Grande do Sul (6\%), somados esses Estados contribuíram com 80,3\% da produção total (Conab, 2019).

$\mathrm{Na}$ agricultura familiar, o milho apresenta grande importância para a subsistência, sendo utilizado diretamente para o consumo humano ou utilizado em outras atividades da propriedade como a alimentação animal, principalmente de aves e suínos (Silveira et al., 2015a). Neste contexto, estima-se que um quinto de todo o milho produzido no Brasil seja consumido dentro da propriedade (Borém et al., 2017).

$\mathrm{Na}$ agricultura familiar, o cultivo de variedades crioulas de milho é a principal alternativa, pois, proporciona bom desempenho nas condições ambientais locais em que são cultivadas (Silveira et al., 2015a). $\mathrm{O}$ uso de sementes crioulas confere baixo custo de produção e permite a independência do produtor no sistema produtivo em relação à necessidade de aquisição das sementes. Nesse sentido, os agricultores familiares resgatam anualmente suas próprias sementes, obtendo plantas selecionadas nas condições edafoclimáticas impostas pelo nível socioeconômico do agricultor, ocasionando assim, um melhoramento da variedade de milho cultivada localmente por vários anos (Abreu et al., 2007).

Nesse contexto, a Universidade Federal dos Vales do Jequitinhonha e Mucuri desenvolve na região do Alto Jequitinhonha, o projeto "Milho Crioulo: multiplicação e conservação das variedades tradicionais" que visa resgatar, multiplicar e conservar diferentes variedades de milho que tenham potencial para utilização pelos agricultores familiares da região, capacitando agricultores e difundindo informação sobre as tecnologias de cultivo da cultura. Deste modo, objetivou-se com este trabalho avaliar o desempenho agronômico e caracterizar por meio de alguns descritores, genótipos de milho crioulo, variedades melhoradas e comerciais para o cultivo em Couto de Magalhães de Minas-MG.

\section{MATERIAL E MÉTODOS}

\section{Material genético}

Os materiais genéticos estudados foram: seis variedades de milho crioulo, duas variedades melhoradas de polinização aberta (populações obtidas pelo décimo quinto ciclo de seleção recorrente interpopulacional pela Universidade Estadual do Norte Fluminense Darcy Ribeiro- UENF) e duas variedades comerciais, conforme Tabela 1.

\section{Local e instalação do experimento}

O experimento foi conduzido na Fazenda Experimental Rio Manso, da Universidade Federal dos Vales do Jequitinhonha e Mucuri (UFVJM), na safra do ano agrícola 2017/2018, em Couto de Magalhães de Minas-MG, situada nas coordenadas geográficas de $18^{\circ} 4^{\prime} 44,55^{\prime}$ ' S e $43^{\circ} 27^{\prime} 23^{\prime \prime} \mathrm{W}$, com altitude de $721 \mathrm{~m}$. O clima local é caracterizado como tropical, com estação seca de inverno (Aw), de acordo com a classificação de Köppen-Geiger, com período seco de abril a setembro. A precipitação média anual é de $1246 \mathrm{~mm}$ e a temperatura média anual fica em torno de $21,5^{\circ} \mathrm{C}$ (Climate-Data, 2017).

O solo onde o experimento foi instalado é classificado como Latossolo Vermelho Amarelo distrófico (Embrapa, 2018), de textura franco-arenosa. O solo foi preparado em sistema de plantio convencional (aração e gradagem), no mês de setembro de 2017. A semeadura foi realizada no dia 25 de setembro de 2017, de forma manual, sendo distribuídas três sementes por covas, à profundidade de $0,05 \mathrm{~m}$, totalizando 150 sementes por parcela. A adubação foi recomendada, conforme resultados de análise de solo visando elevar a fertilidade para níveis que proporcionasse a expressão da máxima produtividade dos genótipos, realizada em duas etapas de modo a fornecer as doses de $127 \mathrm{~kg} \mathrm{ha}^{-1} \mathrm{de} \mathrm{N}, 93 \mathrm{~kg} \mathrm{ha}^{-1} \mathrm{de}$ $\mathrm{P}_{2} \mathrm{O}_{5}$ e $150 \mathrm{~kg} \mathrm{ha}^{-1}$ de $\mathrm{K}_{2} \mathrm{O}$, durante o ciclo da cultura. A adubação de plantio foi realizada com o fertilizante formulado NPK 08-28-16, aplicando-se na linha de plantio a dose de $29,9 \mathrm{~g} \mathrm{~m}^{-1}$.

A emergência das plântulas de milho ocorreu no dia 02 de outubro de 2017. Com 21 dias após a emergência, foi realizado o desbaste, deixando-se uma planta por cova totalizando 50 plantas por parcela, que representou a população de 55.555 plantas.ha ${ }^{-1}$. Aos 30 dias após 
Tabela 1 - Descrição dos genótipos de milho utilizados na safra 2017/2018, em Couto de Magalhães de Minas-MG

\begin{tabular}{lcc}
\hline Genótipos & Origem & Base Genética \\
\hline CR1 & Viçosa-MG & Crioulo \\
CR2 & Viçosa-MG & Crioulo \\
CR3 & Couto de Magalhães de Minas-MG & Crioulo \\
CR4 & Couto de Magalhães de Minas -MG & Crioulo \\
CR5 & São Gonçalo do Rio Preto-MG & Crioulo \\
CR6 & Couto de Magalhães de Minas -MG & Crioulo \\
Piranão & UENF $^{2}$ & Variedade \\
Cimmyti & UENF $^{2}$ & Variedade \\
UFVM 200 & UFV & Variedade Comercial \\
AF 505 & Sakata Seed $^{3}$ & Variedade Comercial \\
\hline
\end{tabular}

${ }^{1}$ Testemunhas: UFVM 200-Registro no MAPA ( $\left.n^{\circ} 12379 / 2002\right)$; AF 505- Registro no MAPA ( $\mathrm{n}^{\circ}$ 28862/2012); ${ }^{2}$ UENF-Universidade Estadual do Norte Fluminense Darcy Ribeiro- RJ; ${ }^{3}$ UFV- Universidade Federal de Viçosa-MG.

o plantio (DAP) realizou-se a adubação de cobertura com uso de sulfato de amônio $(20 \% \mathrm{~N})$ na dose de $45 \mathrm{~g} \mathrm{~m}^{-1}$ e cloreto de potássio $\left(58 \% \mathrm{~K}_{2} \mathrm{O}\right)$ aplicando $15 \mathrm{~g} \mathrm{~m}^{-1} \mathrm{de} \mathrm{K}_{2} \mathrm{O}$. O manejo de plantas daninhas foi realizado por meio de uma capina manual com enxada nas entrelinhas da cultura. A área possui irrigação por aspersão, que foi utilizada para complementar a demanda hídrica dos genótipos de milho apenas nas duas primeiras semanas após o plantio (aproximadamente até o estádio V2), fornecendo uma lâmina de irrigação de $5 \mathrm{~mm} \mathrm{dia}^{-1}$.

O delineamento experimental foi de blocos casualizados, com quatro repetições e dez genótipos de milho. As parcelas foram constituídas de duas linhas de cinco metros de comprimento, com espaçamento de $0,90 \mathrm{~m}$ entre as linhas e $0,20 \mathrm{~m}$ entre plantas.

A maturação fisiológica foi observada em 05 de fevereiro de 2018 e a colheita foi realizada no dia 19 de fevereiro de 2018, de forma manual e, no mesmo momento realizou-se a despalha. As espigas colhidas foram armazenadas em sacos de ráfia. $\mathrm{O}$ material foi transportado para o Laboratório de Olericultura do Departamento de Agronomia da Universidade Federal dos Vales do Jequitinhonha e Mucuri (UFVJM), em Diamantina-MG, onde procedeu às avaliações dos aspectos morfoagronômicos e de produtividade relacionados a espigas e grãos, procedendo a debulha manual para a determinação da produtividade de grãos.

\section{Características agronômicas avaliadas em campo}

Os caracteres avaliados no momento da colheita foram: i) acamamento: percentagem de plantas que estavam com ângulo de inclinação superior a $45^{\circ} \mathrm{em}$ relação à vertical; ii) tombamento (TOM): plantas com o colmo quebrado, abaixo da espiga superior; iii) prolificidade (PRO): número de espigas por planta; iv) número de espigas doentes (NED); e, v) número de espigas atacadas por pragas (NEP).

A morfologia da espiga foi avaliada em cinco espigas por parcela, considerando as seguintes características: i) diâmetro (DE): mensurado com paquímetro digital e expresso em milímetros; ii) comprimento da espiga (CE): definido com auxílio de régua graduada, expresso em centímetros; iii) número médio de fileiras de grãos por espigas (NFG); iv) número médio de grãos por fileira em espigas (NGF); v) forma/tipo da espiga (FE), de acordo com a escala de notas: 1 - cilíndrica, 2 - cônicacilíndrica, 3 - cônica e 4 - arredondada; e, vi) arranjo das carreiras de grãos (ACG): de acordo com a escala de notas - 1- regular, 2 - irregular, 3 - direito e 4 - espiral.

A morfologia dos grãos foi avaliada em cinco grãos por parcela, considerando as seguintes características: i) forma do grão (FG), de acordo com a escala de notas: 1 - contraído, 2 - dentado, 3 - plano, 4 - redondo, 5 pontiagudo e 6 - muito pontiagudo; ii) comprimento do grão (COG), iii) largura (LGF) e iv) espessura (EG), medidos com paquímetro digital e expressos em milímetros.

O desempenho agronômico foi avaliado considerando as seguintes características: i) produtividade de espiga (PE): pesagem das espigas despalhadas $\left(\mathrm{kg} \mathrm{ha}^{-1}\right)$; ii) produtividade de grãos (PROD): pesagem dos grãos sem o sabugo $\left(\mathrm{kg} \mathrm{ha}^{-1}\right)$; e, iii) massa média de cem grãos (M100G): pesagem de 100 grãos em balança analítica com duas casas decimais em três repetições por parcela $(\mathrm{g})$. 


\section{Análise estatística}

A análise de variância foi realizada de acordo com o modelo: $\mathrm{Y}_{i j}=\mu+\mathrm{g}_{i}+\mathrm{b}_{j}+\mathrm{e}_{i j}$, em que: $\mathrm{Y}_{i j}$ : valor observado na parcela que recebeu o genótipo i no bloco $\mathrm{j} ; \mu$ : média geral do experimento; $\mathrm{g}_{\mathrm{i}}$ : efeito do genótipo $\mathrm{i}$, $\mathrm{i}=1,2, \ldots, 10 ; \mathrm{b}_{j}$ : efeito da repetição $\mathrm{j}, \mathrm{j}=1,2, \ldots, 4$; $\mathrm{e}, \mathrm{e}_{i j}$ : erro experimental associado à observação Yij, sendo NID $\left(0, \sigma^{2}\right)$.

Detectada a diferença significativa entre os genótipos de milho nas características avaliadas, efetuouse o teste de média de Tukey a 5\% de probabilidade, para averiguação da comparação entre os genótipos de milho. Para detectar se os 17 descritores avaliados possuem correlação, entre dois a dois estimou-se, coeficiente de correlação de Pearson (Stell et al., 1997).

Sendo: $\mathrm{r}=\frac{\sum(x i-\bar{x})(y i-\bar{y})}{\sqrt{\left(\sum(x i-\bar{x})^{2}\right)\left(\sum(y i-\bar{y})^{2}\right)}}=\frac{\operatorname{cov}(x, Y)}{\sqrt{\sigma_{X}^{2} \sigma_{Y}^{2}}}$, em que: $\operatorname{COV}_{(X, Y)}$

corresponde às estimativas das covariâncias entre as características x e y; $\sigma_{\mathrm{x}}^{2}$ e $\sigma_{\mathrm{y}}^{2}$, correspondem às estimativas das variâncias da característica x e y, respectivamente. Efetuou-se o teste de média de $t$ a $5 \%$ e a $1 \%$ de probabilidade, para averiguação da comparação entre as características avaliadas nos genótipos de milho. Todos os cálculos referentes às análises estatísticas para as características agronômicas foram executados utilizando o software Genes (Cruz, 2013).

\section{RESULTADOS E DISCUSSÃO}

\section{Caracterização agronômica de diferentes genótipos de milho}

Os genótipos CR2 (3,5\%) e CR5 (3,5\%), de milho crioulo, mostraram-se mais suscetíveis ao tombamento (Tabela 2). Já os genótipos de milhos crioulos CR3 $(0,25 \%)$, CR4 (0,5 \%) e CR6 (0,25\%) que são oriundos de Couto de Magalhães de Minas tiveram comportamento similar à variedade comercial UFVM $200(0,25 \%)$, apresentando maior resistência ao tombamento. O tombamento das plantas de milho é uma característica relacionada às condições ambientais, como, a ocorrência de ventos fortes, e também pelo diâmetro do colmo da planta. O maior índice de tombamento pode comprometer a produção de grãos dos genótipos mais susceptíveis, uma vez que a queda da planta acarreta na redução na produção de fotoassimilados e também ocasionar em perdas no campo relacionadas à dificuldade na colheita mecanizada (Cruz et al., 2006).

A variedade Piranão apresentou maior prolificidade $\left(1,29\right.$ espigas planta $\left.^{-1}\right)$ não diferindo do genótipo CR6 $(1,03)$ e da variedade comercial UFVM 200 (0.99). Todas as variedades crioulas estudadas apresentaram prolificidade similar apresentada pelas variedades comerciais UFVM 200 e AF-505 e a variedade Cimmyti.

Os genótipos CR1 e a variedade Piranão apresentaram mais espigas atacadas por pragas com 24,25 e 23,25, respectivamente. Em contrapartida, estes apresentaram o menor número de espigas doentes, sendo 0 e 1 espiga, respectivamente, diferindo da variedade comercial AF 505, que apresentou 4,5 espigas doentes (Tabela 2). Os genótipos CR2, CR3, CR4, CR5 e CR6 apresentaram baixo índice de ataque de pragas na espiga, sendo similares ao índice das variedades UFVM 200, Cimmyti e AF-505.

A avaliação do número de espigas atacadas e doentes implica na determinação de variedades resistentes a pragas e doenças presentes em determinada região de cultivo, sendo o método mais eficiente, racional e econômico para evitar ou diminuir os danos (Rosset et al., 2013).

Os seis genótipos de milho crioulo não diferiram entre si para aspectos relacionados ao comprimento da espiga (Tabela 3). A variedade Piranão apresentou o menor comprimento de espiga $(14,41 \mathrm{~cm})$. Em relação ao diâmetro de espiga, as variedades Piranão $(42,49$ $\mathrm{mm})$ e Cimmyti (42,50 $\mathrm{mm}$ ) se diferiram dos genótipos CR 4 (50,9 mm) e CR3 (49,02 mm) e da variedade comercial UFVM 200 (48,59 mm). Portanto, os dois maiores diâmetros de espiga foram observados em genótipos de milho crioulo oriundos de Couto de Magalhães de Minas.

Não houve diferença para a forma da espiga, sendo consideradas cônicas - cilíndricas. As diferenças morfológicas das espigas podem ser observadas na Figura 1. Em análise do arranjo de carreiras de grãos observou que somente a variedade AF 505 diferenciou dos demais, apresentando arranjo regular dos grãos. Os genótipos CR2 $(12,1)$ e CR5 $(10,7)$ e as variedades Piranão $(11,5)$ e Cimmyti $(12,5)$, diferiram da variedade comercial AF 505 (16,2). O genótipo CR5 apresentou o menor número de grãos por fileira, porém não diferiu das variedades Cimmyti (32,9), Piranão (35,25), AF 500 $(35,7)$ e UFVM $200(35,75)$. Os genótipos CR6 $(39,25)$ 
Tabela 2 - Tombamento (\%); Prolificidade (espigas planta-1); Número de espigas com pragas (NEP); Número de espigas doentes (NED) em diferentes genótipos de milho em Couto de Magalhães-MG, safra 2017/ 2018

\begin{tabular}{|c|c|c|c|c|}
\hline Genótipos & Tombamento (\%) & Prolificidade & NEP & NED \\
\hline CR1 & $0,75 \mathrm{ab}$ & $0,95 \mathrm{~b}$ & $24,25 \mathrm{a}$ & $0,0 \mathrm{~b}$ \\
\hline $\mathrm{CR} 2$ & $3,50 \mathrm{a}$ & $0,79 \mathrm{~b}$ & $12,75 \mathrm{ab}$ & $0,75 \mathrm{~b}$ \\
\hline CR3 & $0,25 \mathrm{~b}$ & $0,91 \mathrm{~b}$ & $9,75 \mathrm{~b}$ & $1,25 \mathrm{~b}$ \\
\hline CR4 & $0,50 \mathrm{~b}$ & $0,94 \mathrm{~b}$ & $13,75 \mathrm{ab}$ & $3,0 \mathrm{ab}$ \\
\hline CR5 & $3,50 \mathrm{a}$ & $0,78 \mathrm{~b}$ & $13,25 \mathrm{ab}$ & $0,0 \mathrm{~b}$ \\
\hline CR6 & $0,25 \mathrm{~b}$ & $1,03 \mathrm{ab}$ & $9,75 \mathrm{~b}$ & $1,0 \mathrm{~b}$ \\
\hline Piranão & $1,75 \mathrm{ab}$ & $1,29 \mathrm{a}$ & 23,25 a & $1,0 \mathrm{~b}$ \\
\hline Cimmyti & $0,75 \mathrm{ab}$ & $0,90 \mathrm{~b}$ & $15,0 \mathrm{ab}$ & $1,0 \mathrm{~b}$ \\
\hline UFVM 200 & $0,25 \mathrm{~b}$ & $0,99 \mathrm{ab}$ & $10,75 \mathrm{~b}$ & $2,0 \mathrm{ab}$ \\
\hline AF 505 & $1,0 \mathrm{ab}$ & $0,98 \mathrm{~b}$ & $18,50 \mathrm{ab}$ & $4,50 \mathrm{a}$ \\
\hline Média & 1,25 & 0,95 & 15,10 & 1,45 \\
\hline $\mathrm{CV}(\%)$ & 95,15 & 13,36 & 33,48 & 90,01 \\
\hline
\end{tabular}

Médias seguidas pela mesma letra, em cada coluna, não diferem entre si pelo teste de Tukey a 5\% de probabilidade.

Tabela 3 - Comprimento espiga (CE), diâmetro espiga (DE), forma espiga (FE), arranjo carreira de grãos (ACG), número fileira de grãos (NFG), número de grãos por fileira (NGF) em diferentes genótipos de milho em Couto de Magalhães-MG, safra 2017/2018

\begin{tabular}{lcccccc}
\hline Genótipos & CE $(\mathrm{cm})$ & DE $(\mathrm{mm})$ & FE & ACG & NFG & NGF \\
\hline CR1 & $17,33 \mathrm{a}$ & $44,29 \mathrm{bcd}$ & $1,9 \mathrm{a}$ & $3,8 \mathrm{a}$ & $13,0 \mathrm{cde}$ & $37,7 \mathrm{ab}$ \\
CR2 & $16,88 \mathrm{a}$ & $43,05 \mathrm{~cd}$ & $1,95 \mathrm{a}$ & $3,35 \mathrm{a}$ & $12,1 \mathrm{def}$ & $35,65 \mathrm{abc}$ \\
CR3 & $17,45 \mathrm{a}$ & $49,02 \mathrm{ab}$ & $2,55 \mathrm{a}$ & $3,8 \mathrm{a}$ & $13,8 \mathrm{bcd}$ & $37,3 \mathrm{ab}$ \\
CR4 & $17,55 \mathrm{a}$ & $50,90 \mathrm{a}$ & $1,75 \mathrm{a}$ & $3,75 \mathrm{a}$ & $13,7 \mathrm{~cd}$ & $38,0 \mathrm{a}$ \\
CR5 & $17,95 \mathrm{a}$ & $45,35 \mathrm{abcd}$ & $2,45 \mathrm{a}$ & $2,95 \mathrm{a}$ & $10,7 \mathrm{f}$ & $31,75 \mathrm{c}$ \\
CR6 & $17,07 \mathrm{a}$ & $47,81 \mathrm{abcd}$ & $2,5 \mathrm{a}$ & $3,15 \mathrm{a}$ & $15,7 \mathrm{ab}$ & $39,25 \mathrm{a}$ \\
Piranão & $14,41 \mathrm{~b}$ & $42,49 \mathrm{~d}$ & $1,85 \mathrm{a}$ & $2,45 \mathrm{ab}$ & $11,5 \mathrm{ef}$ & $35,25 \mathrm{abc}$ \\
Cimmyti & $16,18 \mathrm{ab}$ & $42,50 \mathrm{~d}$ & $2,05 \mathrm{a}$ & $3,55 \mathrm{a}$ & $12,5 \mathrm{def}$ & $32,9 \mathrm{bc}$ \\
UFVM 200 & $16,2 \mathrm{ab}$ & $48,59 \mathrm{abc}$ & $2,15 \mathrm{a}$ & $3,45 \mathrm{a}$ & $14,9 \mathrm{abc}$ & $35,75 \mathrm{abc}$ \\
AF 505 & $16,2 \mathrm{ab}$ & $43,87 \mathrm{bcd}$ & $2,45 \mathrm{a}$ & $1,15 \mathrm{~b}$ & $16,2 \mathrm{a}$ & $35,7 \mathrm{abc}$ \\
Média & 16,73 & 45,79 & 2,16 & 3,14 & 13,41 & 35,92 \\
CV(\%) & 5,74 & 5,02 & 25,86 & 19,04 & 5,94 & 5,56 \\
\hline
\end{tabular}

Médias seguidas pela mesma letra, em cada coluna, não diferem entre si pelo teste de Tukey a 5\% de probabilidade.

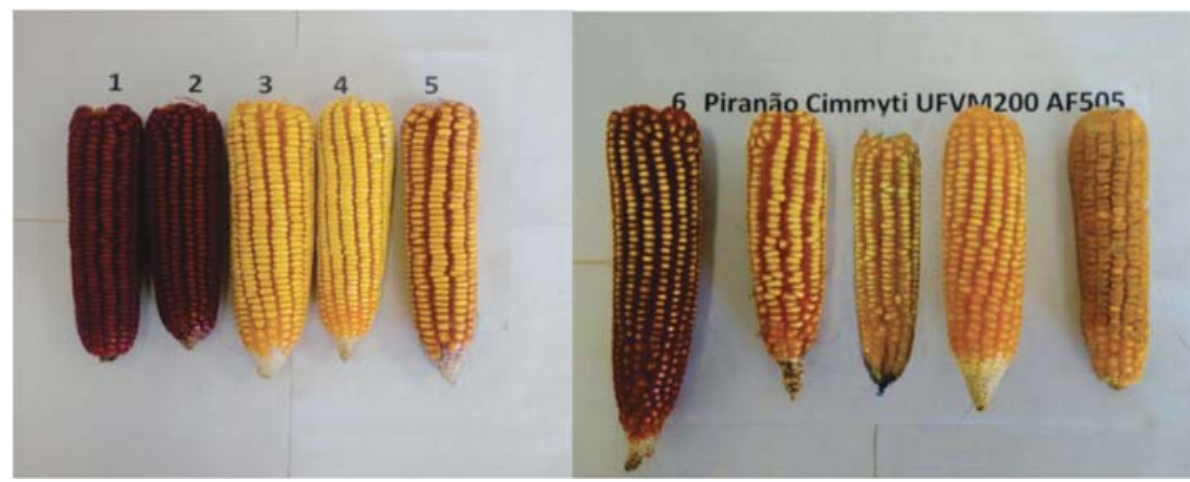

Figura 1 - Características da espiga em diferentes genótipos de milho. 
e CR4 $(38,0)$ se destacaram com o maior número de grãos por fileira.

O genótipo CR5 apresentou os maiores valores de largura de grãos por fileira (11,08 mm), espessura do grão $(4,45 \mathrm{~mm})$ e para o comprimento de grãos $(7,38$ $\mathrm{mm}$ ), não diferiu do CR4 que apresentou o maior valor $(8,71 \mathrm{~mm})$ (Tabela 4). O inverso ocorreu com a variedade de AF 505, que apresentou os menores valores de espessura do grão $(2,53 \mathrm{~mm})$, largura do grão por fileira $(7,13 \mathrm{~mm})$ e comprimento do grão $(5,05 \mathrm{~mm})$, diferente das demais variedades e apresentou grãos mais estreitos e enrugados. Esse formato está relacionado ao teor de amido presente no grão e a elevada perda do teor de umidade durante o processo de maturação (Borém et al., 2017). Estas diferenças morfológicas entre os grãos dos diferentes genótipos de milho estão evidenciadas na Figura 2, sendo possível perceber a variabilidade principalmente quanto à cor dos grãos desses genótipos avaliados.

O genótipo CR4, destacou-se com maior produtividade de espiga (Tabela 5), com 9032,21 kg $\mathrm{ha}^{-1}$, e consequentemente apresentou um dos melhores valor de produtividade de grãos 7038,02 $\mathrm{kg} \mathrm{ha}^{-1}$, não diferindo estaticamente quanto a produtividade de grãos dos genótipos CR6 (6893,21 kg ha-1), CR3 (6337,21 $\left.\mathrm{kg} \mathrm{ha}^{-1}\right)$ e das variedades UFVM $200\left(7063,38 \mathrm{~kg} \mathrm{ha}^{-}\right.$ $\left.{ }^{1}\right)$ e Piranão (6724,48 $\left.\mathrm{kg} \mathrm{ha}^{-1}\right)$, sendo que estes valores superaram a produtividade média nacional de milho $2017 / 2018\left(1^{\mathrm{a}} \mathrm{e} 2^{\mathrm{a}} \mathrm{safra}\right.$ ) que foi de $4857 \mathrm{~kg} \mathrm{ha}^{-1}$ (Conab, 2019).

Tabela 4 - Largura do grão na fileira (LGF); Comprimento do grão (COG); Espessura do grão (EG); Forma do grão (FG) em diferentes genótipos de milho. Couto de Magalhães-MG, safra 2017/2018

\begin{tabular}{lcccc}
\hline Genótipos & LGF $(\mathrm{mm})$ & COG $(\mathrm{mm})$ & EG $(\mathrm{mm})$ & ${ }^{2} \mathrm{FG}$ \\
\hline CR1 & $9,16 \mathrm{bcd}$ & $7,35 \mathrm{abc}$ & $3,89 \mathrm{ab}$ & $4,26 \mathrm{a}$ \\
CR2 & $9,6 \mathrm{bc}$ & $7,52 \mathrm{abc}$ & $3,71 \mathrm{ab}$ & $2,55 \mathrm{a}$ \\
CR3 & $9,45 \mathrm{bc}$ & $8,37 \mathrm{ab}$ & $3,73 \mathrm{ab}$ & $2,05 \mathrm{a}$ \\
CR4 & $9,80 \mathrm{~b}$ & $8,71 \mathrm{a}$ & $4,45 \mathrm{a}$ & $2,7 \mathrm{a}$ \\
CR5 & $11,08 \mathrm{a}$ & $7,38 \mathrm{abc}$ & $3,61 \mathrm{ab}$ & $3,1 \mathrm{a}$ \\
CR6 & $8,09 \mathrm{de}$ & $7,93 \mathrm{ab}$ & $3,16 \mathrm{bc}$ & $2,9 \mathrm{a}$ \\
Piranão & $9,57 \mathrm{bc}$ & $6,52 \mathrm{bcd}$ & $3,69 \mathrm{ab}$ & $3,0 \mathrm{a}$ \\
Cimmyti & $9,13 \mathrm{bcd}$ & $5,89 \mathrm{~cd}$ & $3,59 \mathrm{ab}$ & \\
UFVM 200 & $8,55 \mathrm{~cd}$ & $7,40 \mathrm{abc}$ & $2,53 \mathrm{c}$ & $3,0 \mathrm{a}$ \\
AF 505 & $7,13 \mathrm{e}$ & $5,05 \mathrm{~d}$ & 3,66 & $1,0 \mathrm{~b}$ \\
Média & 9,16 & 7,21 & 10,29 & 2,68 \\
CV (\%) & 4,83 & 10,60 & 5,61 \\
\hline
\end{tabular}

Médias seguidas pela mesma letra, em cada coluna, não diferem entre si pelo teste de Tukey a 5\% de probabilidade.

Revista Brasileira de Agropecuária Sustentável (RBAS), v.9, n.2, p.33-43, Julho, 2019
No trabalho de Reis (2009) foi observado valores menores de produtividade de espiga para a variedade Piranão (7960 $\left.\mathrm{kg} \mathrm{ha}^{-1}\right)$ do que no presente trabalho em Couto de Magalhães de Minas (8589,09 $\left.\mathrm{kg} \mathrm{ha}^{-1}\right)$, e valores maiores para a variedade Cimmyti $\left(8870 \mathrm{~kg} \mathrm{ha}^{-1}\right)$ em comparação no presente trabalho $\left(5729,97 \mathrm{~kg} \mathrm{ha}^{-1}\right)$.

Por outro lado, o genótipo CR5 apresentou a menor produtividade de espiga $\left(3918,08 \mathrm{~kg} \mathrm{ha}^{-1}\right)$ e a menor produtividade de grãos $\left(2725,53 \mathrm{~kg} \mathrm{ha}^{-1}\right)$, e já vinha demostrando seu baixo desempenho agronômico nas avaliações anteriores, apresentadas na Tabela 3 , onde obteve os menores valores de NFG (número de fileiras de grãos) e NGF (número de grãos por fileira). Porém, esse genótipo apresentou a maior massa de cem grãos $(46,35 \mathrm{~g})$ (Tabela 5). A variedade comercial AF 505 apresentou a menor massa de cem grãos $(13,67)$.

De maneira geral, os genótipos crioulos podem ser menos produtivos quando comparados aos comerciais. Isso porque no mercado, têm-se variedades híbridas com potencial para chegar a produtividades de grãos iguais ou maiores que $12000 \mathrm{~kg} \mathrm{ha}^{-1}$, demandando um manejo altamente tecnológico, obedecendo ao estande adequado, solos com boas condições químicas, físicas e biológicas para o desenvolvimento radicular, fornecimento de elevados níveis de adubação de plantio e cobertura para atender as altas exigências nutricionais de macro e micronutrientes; água em quantidade e qualidade suficiente para não sofrer déficits hídricos ao longo do ciclo da cultura e investimento para manter a lavoura livre de plantas competidoras, pragas e doenças (Paterniani et al., 2000). 
Diversas das exigências listadas para que essas variedades alcancem os altos tetos de produtividade de grãos não são ofertadas dentro da realidade produtiva de um agricultor familiar. Além disso, as condições edafoclimáticas distintas daquelas em que as sementes híbridas foram obtidas ocasiona grandes quebras de produtividade, levando a variedade por vezes a produzir um quarto do seu potencial. Porém, Silveira et al. (2015b), avaliando a produtividade de genótipo de milho crioulo, no município de Cruz Alta no Estado do Rio Grande do Sul, obteve produtividades equivalente a $4.667,59 \mathrm{~kg} \mathrm{ha}^{-1}$, próximo da média nacional na safra de 2014/2015 (Conab, 2015), que foi de $4.892 \mathrm{~kg} \mathrm{ha}^{-1}$.

De acordo com Silveira et al. (2015a), quando há o emprego de baixas tecnologias de cultivo, o uso de milhos crioulos torna-se uma técnica viável

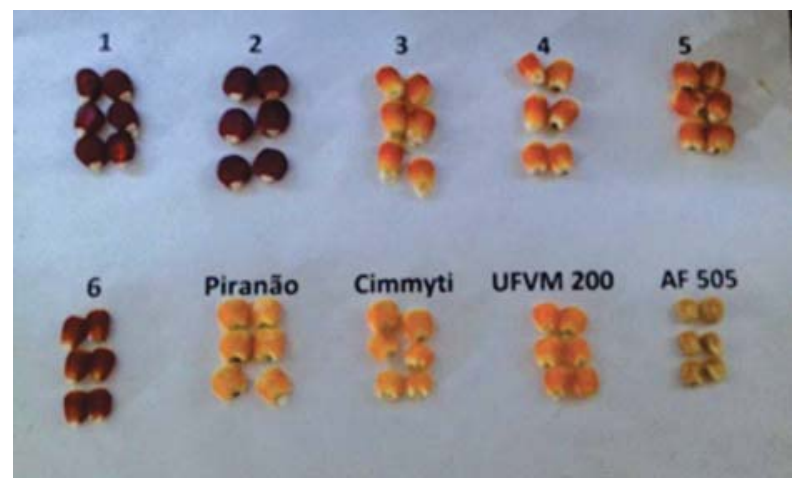

Figura 2 - Características do grão em diferentes genótipos de milho economicamente, devido o desempenho semelhante ou até mesmo superior em relação a variedades comerciais melhoradas e híbridos. Isso pode ser comprovado nos trabalhos que compararam variedades de milho crioulo aos híbridos em diferentes níveis tecnológicos de cultivo no Norte de Minas Gerais (Araújo et al., 2013). Portanto, não significa que milhos crioulos sejam adequados apenas para cultivo em sistema de baixa tecnologia de produção, no âmbito da agricultura familiar, pois haverá incrementos positivos em produtividade com a adoção de melhores técnicas de cultivo em relação àquelas restritivas em que está sendo submetido (Bianchetto et al., 2017).

Um exemplo disso foi o trabalho realizado por Tibães (2018), com milho crioulo irrigado em Couto de Magalhães de Minas-MG, onde a produtividade de grãos respondeu linearmente ao aumento das doses de nitrogênio e potássio fornecidos em cobertura, de modo que foi obtida uma produtividade de 8.575 $\mathrm{kg} \mathrm{ha}^{-1}$, na maior dose avaliada $\left(210 \mathrm{~kg} \mathrm{ha}^{-1} \mathrm{de} \mathrm{Ne}\right.$ $168 \mathrm{~kg} \mathrm{ha}^{-1} \mathrm{de}_{2} \mathrm{O}$ ). Esse mesmo genótipo, no presente trabalho (CR1), mesmo estando adequadamente nutrido, produziu apenas 4916,48 $\mathrm{kg} \mathrm{ha}^{-1}$ (Tabela 5), uma vez que sofreu uma condição de elevado déficit hídrico durante o seu ciclo de cultivo, diferentemente do trabalho de Tibães (2018), onde o mesmo recebeu aporte de irrigação. No entanto, no presente trabalho houve genótipos de milho crioulo que produziram mais de $6000 \mathrm{~kg} \mathrm{ha}^{-1}$, mesmo em condição de baixa precipitação e altas temperaturas.

Tabela 5 - Produtividade de espigas e grãos $\left(\mathrm{kg} \mathrm{ha}^{-1}\right)$ e massa de cem grãos (g) de diferentes genótipos de milho em Couto de Magalhães-MG, safra 2017/2018

\begin{tabular}{lccc}
\hline Genótipos & Produtividade de espiga $\left(\mathrm{kg} \mathrm{ha}^{-1}\right)$ & Produtividade de grãos $\left(\mathrm{kg} \mathrm{ha}^{-1}\right)$ & Massa cem Grãos $(\mathrm{g})$ \\
\hline CR1 & $6372,41 \mathrm{bcd}$ & $4916,48 \mathrm{bc}$ & $33,77 \mathrm{bc}$ \\
CR2 & $5414,57 \mathrm{de}$ & $4193,39 \mathrm{~cd}$ & $30,65 \mathrm{bc}$ \\
CR3 & $7930,58 \mathrm{abc}$ & $6337,21 \mathrm{ab}$ & $33,85 \mathrm{bc}$ \\
CR4 & $9032,21 \mathrm{a}$ & $7038,02 \mathrm{a}$ & $38,62 \mathrm{ab}$ \\
CR5 & $3918,08 \mathrm{e}$ & $2725,53 \mathrm{~d}$ & $46,35 \mathrm{a}$ \\
CR6 & $8456,84 \mathrm{ab}$ & $6893,21 \mathrm{a}$ & $29,075 \mathrm{c}$ \\
Piranão & $8589,09 \mathrm{ab}$ & $6724,48 \mathrm{ab}$ & $29,00 \mathrm{c}$ \\
Cimmyti & $5729,97 \mathrm{cde}$ & $4191,61 \mathrm{~cd}$ & $26,22 \mathrm{c}$ \\
UFVM 200 & $8629,62 \mathrm{ab}$ & $7063,38 \mathrm{a}$ & $31,85 \mathrm{bc}$ \\
AF 505 & $5438,92 \mathrm{de}$ & $4151,51 \mathrm{~cd}$ & $13,67 \mathrm{~d}$ \\
Média & 6951,23 & 5423,48 & 31,30 \\
CV(\%) & 14,08 & 13,98 & 10,94 \\
\hline
\end{tabular}

Médias seguidas pela mesma letra, em cada coluna, não diferem entre si pelo teste de Tukey a 5\% de probabilidade. 


\section{Correlações fenotípicas entre características agronômicas em milho}

A avaliação entre as características agronômicas é de extrema importância para auxiliar na seleção de importantes atributos em determinada região de cultivo. Para isso, tem-se a utilização de ferramentas estatísticas como os coeficientes de correlação, um requisito básico para quantificar a magnitude e a direção das influências de determinada característica sobre outra ou quando se pretende melhorar várias características simultaneamente (Cruz et al., 2012).

A característica tombamento está correlacionada negativamente ao peso de espiga $(-0,7)$, produtividade de grãos $(-0,7)$ e ao número de fileira de grãos $(-0,7)$ (Tabela 6), ou seja, à medida que aumenta o número de plantas tombadas, ocorre o decréscimo das referidas variáveis. Isso se deve ao fato de que o colmo do milho, além de suportar as folhas e partes florais, serve também como órgão de reserva de fotoassimilados. Após a floração, o fluxo de fotoassimilados é direcionado prioritariamente ao enchimento de grãos (Fancelli \& Dourado Neto, 2000).

Segundo Gomes et al. (2010) o acamamento e tombamento muitas vezes causa a ruptura dos tecidos, o que interrompe a vascularização do colmo e impede a recuperação da planta, interferindo na estrutura anatômica essencial para o transporte de água e nutrientes e, quanto mais cedo se manifesta no ciclo de vida da planta menor serão o rendimento e a qualidade dos grãos

A característica prolificidade resultou em correlação negativa com comprimento de espiga $(-0,8)$ e espessura do grão $(-0,7)$ (Tabela 6$)$, demonstrando que quando aumenta o número de espigas em uma mesma planta, diminui seu comprimento e a espessura do grão. No estádio V12, a distribuição de chuvas, a disponibilidade de nutrientes e a duração do intervalo compreendido entre o estádio V12 e R1 (florescimento) constituem fatores decisivos na definição da produção e rendimento da cultura, principalmente quanto ao tamanho e ao número de espigas (Borém et al., 2017).

Em uma situação de estresse, a planta tende a regular suas relações fonte-dreno, priorizando características que garantam sua perpetuação, o que pode afetar a espessura do grão. Estas relações podem ser alteradas sobremaneira pelas condições de solo, clima, estádio fisiológico e nível de estresse da cultura (Fancelli \& Dourado Neto, 2000). As plantas prolíferas são geralmente mais tolerantes a condições adversas, devido a sua

Tabela 6 - Correlação entre caracteres morfológicos e produtivos em diferentes genótipos de milho em Couto de Magalhães de Minas-MG na safra 2017/2018

\begin{tabular}{|c|c|c|c|c|c|c|c|c|c|c|c|c|c|c|c|c|c|}
\hline CARÁTER & TO & PR & NED & NEP & $\mathrm{CE}$ & $\mathrm{DE}$ & $\mathrm{FE}$ & $\mathrm{PE}$ & PROD & M100G & ACG & NFG & NGF & LGF & $\mathrm{COG}$ & EG & FG \\
\hline TO & $\ldots$ & $-0,4$ & 0,09 & $-0,3$ & 0,08 & $-0,5$ & $-0,08$ & $-0,7 *$ & $-0,7 *$ & 0,3 & $-0,2$ & $-0,7 *$ & $-0,6$ & 0,6 & $-0,1$ & 0,5 & 0,1 \\
\hline PR & & $\ldots$ & 0,5 & $-0,02$ & $-0,8^{*}$ & $-0,1$ & $-0,2$ & 0,6 & 0,6 & $-0,4$ & $-0,3$ & 0,2 & 0,2 & $-0,3$ & $-0,2$ & $-0,7 *$ & 0,04 \\
\hline NEP & & & & $\ldots$ & 0,1 & 0,2 & 0,1 & $-0,1$ & $-0,1$ & $-0,5$ & $-0,6$ & 0,6 & 0,09 & $-0,6$ & $-0,3$ & $-0,6$ & $-0,9 * *$ \\
\hline $\mathrm{CE}$ & & & & & $\ldots$ & 0,3 & 0,3 & $-0,3$ & $-0,3$ & 0,6 & 0,4 & 0,1 & 0,2 & 0,3 & 0,6 & 0,6 & 0,07 \\
\hline $\mathrm{DE}$ & & & & & & $\ldots$ & 0,2 & 0,6 & 0,6 & 0,4 & 0,4 & 0,4 & 0,5 & 0,03 & $0,8^{*}$ & 0,1 & 0,1 \\
\hline $\mathrm{PE}$ & & & & & & & & $\ldots$ & $1,0 * *$ & $-0,01$ & 0,3 & 0,4 & $0,7^{*}$ & 0,2 & 0,5 & $-0,3$ & $-0,3$ \\
\hline PROD & & & & & & & & & $\ldots$ & $-0,03$ & 0,3 & 0,4 & $0,7^{*}$ & $-0,3$ & 0,5 & $-0,3$ & 0,3 \\
\hline M100G & & & & & & & & & & $\ldots$ & $0,7^{*}$ & $-0,6$ & $-0,2$ & $0,9 * *$ & $0,7^{*}$ & $0,8^{*}$ & 0,6 \\
\hline ACG & & & & & & & & & & & $\ldots$ & $-0,3$ & 0,2 & 0,5 & $0,7^{*}$ & $0,8^{*}$ & $0,7^{*}$ \\
\hline NFG & & & & & & & & & & & & $\ldots$ & 0,6 & $-0,9 * *$ & $-0,09$ & $-0,6$ & $-0,5$ \\
\hline NGF & & & & & & & & & & & & & $\ldots$ & $-0,4$ & 0,5 & $-0,2$ & $-0,03$ \\
\hline LGF & & & & & & & & & & & & & & $\ldots$ & 0,5 & $0,8 * *$ & 0,6 \\
\hline EG & & & & & & & & & & & & & & & & $\ldots$ & $0,7^{*}$ \\
\hline
\end{tabular}

Tombamento (TO); Prolificidade (PR); Número de espigas doentes (NED); Número de espigas com praga (NEP); Comprimento de espiga (CE); Diâmetro da espiga (DE); Forma da espiga (FE); Produtividade de espiga (PE); Produtividade de grãos (PROD); Massa cem grãos (M100G); Arranjo de carreira de grãos (ACG); Número de fileira de grãos (NFG); Número de grãos por fileira (NGF); Largura do grão na fileira (LGF); Comprimento do grão (COG); Espessura do grão (EG); Forma do grão (FG). **Significativo a 1 e * 5\% de probabilidade pelo teste $t$. 
capacidade inerente de desenvolver ao menos uma espiga sob estresse e mais de uma quando as condições ambientais são propicias, podendo incrementar o rendimento quando a densidade está abaixo do ideal (Sangoi et al., 2000).

O número de espigas atacadas por pragas expressou correlação negativa com a forma do grão $(-0,9)$ (Tabela 6). Este fato pode ser devido a forma do grão é definido pela estrutura do endosperma e tamanho do gérmen, fatores que determinam sua consistência influenciando a resistência ao ataque de insetos, sendo diferente para cada variedade de milho (Santos, 2015).

Para diâmetro da espiga, observou correlação positiva com comprimento do grão $(0,8)$, ou seja, na medida em que aumenta o diâmetro da espiga aumenta também o comprimento do grão. A resposta deste fato está na competição entre grãos por espaço na espiga, ou seja, espigas de maior diâmetro permitem menor competição entre os grãos por espaço, favorecendo seu crescimento. Mais duas correlações realizadas no trabalho são influenciadas pela competição entre grãos por espaço na espiga, o caráter largura do grão por fileira que apresentou correlação positiva com espessura do grão $(0,8)$ e o número de fileira de grãos que apresentou correlação negativa com largura do grão por fileira (0,9) (Tabela 6).

O peso da espiga apresentou correlação positiva com a produtividade de grãos $(1,0)$ e o número de grãos por fileira $(0,7)$, que por vez também apresentou correlação positiva com a produtividade de grãos $(0,7)$ (Tabela 6). Segundo Pereira et al. (2018), a produtividade de milho depende basicamente plantas por hectare, número de espigas e número de grãos por fileira, sendo este último influenciado pela porcentagem de fertilização, número e comprimento das fileiras de grãos. Lopes et al. (2007), encontraram, em experimentos de diferentes híbridos de milho em Santa Maria-RS, o número de grãos por fileira na espiga como componente que apresentou a maior correlação total com o rendimento e, quando utilizaram duas variáveis no modelo na análise de trilha, o componente número de grãos/fileira e número de fileiras/espiga explicaram $47 \%$ das variações de produtividade de grãos.

A massa de cem grãos apresentou correlação positiva com os caráteres arranjo da carreira de grãos $(0,7)$, largura do grão na fileira $(0,9)$, comprimento do grão $(0,7)$ e espessura do grão $(0,8)$ (Tabela 6$)$. Fato explicado pela relação direta dos caráteres com o volume do grão, o que confere as dimensões para deposição do amido. No estádio V7, ocorre uma acentuada deposição de amido, caracterizando um período exclusivamente destinado ao ganho de peso por parte do grão (Fancelli \& Dourado Neto, 2000).

O caráter arranjo da carreira de grãos apresentou correlação positiva com os caráteres comprimento do grão $(0,7)$, espessura do grão $(0,7)$ e a forma de grão $(0,8)$ (Tabela 6$)$. O arranjo de carreira de grãos pode aumentar ou diminuir o espaço na espiga para o desenvolvimento dos grãos, além de estar relacionado à eficiência da polinização e ao estresse déficit hídrico (Fancelli e Dourado Neto, 2000).

A espessura do grão apresentou correlação positiva com a forma do grão $(0,7)$ (Tabela 6$)$. Este fato devese a forma determinada pela textura do grão, por exemplo, os grãos duros, apresentam textura dura, tem camada fina de endosperma vítreo no topo do grão e é o que mantém a superfície superior externa da semente com aspecto arredondado em todos os estádios de maturidade da planta; já o milho de textura doce apresenta suas dimensões contraídas (Borém et al., 2017).

Diante das correlações fenotípicas significativas encontradas entre as características agronômicas nos diferentes genótipos de milho, a seleção simultânea entre plantas de menor tombamento, maiores pesos de espigas e número de fileira de grãos presumem ser mais apropriado para proporcionar ganhos satisfatórios na produtividade de grãos dos milhos. Isso demonstra que na prática, tem-se necessidade da avaliação do caráter de mais fácil determinação para que o objetivo seja alcançado (produtividade de grãos), pois a seleção será efetuada de forma indireta também para o outro caráter, reduzindo assim o tempo gasto com avaliações.

\section{CONCLUSÕES}

Os genótipos de milhos crioulos CR3, CR4 e CR6 que são oriundos de Couto de Magalhães de Minas tiveram desenvolvimento similar à variedade comercial UFVM 200, apresentando maior resistência ao tombamento, além de apresentarem produtividade de grãos similares à variedade comercial UFVM 200 e a variedade de polinização aberta Piranão, superando a média nacional do ano-safra, mostrando assim desempenhos agronômicos satisfatórios para o Vale do Jequitinhonha. 
Todas as variedades crioulas estudadas apresentaram prolificidade similar à apresentada pelas variedades comerciais e pela variedade de polinização aberta Cimmyti. Das seis variedades crioulas estudadas, apenas a CR1 obteve alto índice de ataque de pragas, as demais tiveram resposta similar às variedades comerciais e de polinização aberta.

\section{AGRADECIMENTOS}

Os autores agradecem ao Projeto Milho Crioulo pelos recursos disponibilizados para o desenvolvimento da pesquisa e ao Professor Dr. Messias Gonzaga Pereira pela doação das sementes das variedades melhoradas Piranão e Cimmyti, desenvolvidas na Universidade Estadual do Norte Fluminense Darcy Ribeiro.

\section{LITERATURA CITADA}

ABREU, L.; CANSI, E.; JURIATTI, C. Avaliação do rendimento sócio-econômico de variedades crioulas e híbridos comerciais de milho na microrregião de Chapecó. Revista Brasileira de Agroecologia, v.2, n.1, p.1230-1233, 2007.

AGÊNCIA BRASIL. Produção e exportação de milho devem crescer na safra 2018/2019.

Economia, agosto de 2018. Disponível em: <http:// agenciabrasil.ebc.com.br/economia/noticia/201808/producao-e-exportacao-de-milho-devem-crescerna-safra-20182019>. Acesso em: 10 de jan. 2019.

ARAÚJO, A.V.; BRANDÃO JUNIOR, D.S.; FERREIRA, I.C.P.V.; COSTA, C.A.; PORTO, B.B.A. Desempenho agronômico de variedades crioulas e híbridos de milho cultivados em diferentes sistemas de manejo. Revista Ciência Agronômica, v. 44, n. 4, p. 885-892, 2013.

BIANCHETTO, R.; FONTANIVE, D.E.; CEZIMBRA, J.C.G.; KRYNSKI, Â.M.; RAMIRES, M. F.; ANTONIOLLI, Z. I; SOUZA, E. L. Desempenho agronômico de milho crioulo em diferentes níveis de adubação no Sul do Brasil. Revista Eletrônica Científica da UERGS, v.3, n.3, p. 528-545, 2017.

BORÉM, A; GALVÃO, J.C.C.; PIMENTEL, M.A. Milho: do plantio à colheita. In: BRESOLIN, M.; PONS, A. L. (Eds.) Botânica do milho. Viçosa: UFV, 2017. p. 69-72.
CLIMATE-DATA. Clima: Couto de Magalhães de Minas - MG. 2019. Disponível em: <https:// pt.climate-data.org/location/176215/>. Acesso em: 18 de agosto de 2017.

CONAB. Companhia Nacional de

Abastecimento. Boletim Grãos maio - resumo 2019 -Tabela de Levantamento. Disponível em: $<$ https://www.conab.gov.br/component/k2/item/ download/ 25906 fda82a3234ee47c250f01b341a633350>. Acesso em: 17 de mai de 2019.

CONAB. Companhia Nacional de Abastecimento. Levantamento da safra de grãos. v.2, n.6, mar. 2015. Disponível em: $<$ https://www.conab.gov.br/info-agro/safras/ graos/boletim-da-safra-de-graos\& $\mathrm{t}=2>$. Acesso em 30 de abril de 2018.

CRUZ, J.C.; KONZEN, E.A.; PEREIRA FILHO, I.A.; MARRIEL, I.E.; CRUZ, I.; DUARTE, J.O.; OLIVEIRA, M.F.; ALVARENGA, R.C. Produção de milho orgânico na agricultura familiar. Circular técnica 81, p.17, 2006.

CRUZ, C.D.; REGAZZI, A.J.; CARNEIRO, P.C.S. Modelos biométricos aplicados ao melhoramento genético. Viçosa: UFV, 2012. $514 \mathrm{p}$.

CRUZ, C.D. Genes: a software package for analysis in experimental statistics and quantitative genetics. Acta Scientiarum Agronomy, v.35, n.3, p.271-276, 2013. http:// dx.doi.org/10.4025/actasciagron.v35i3.21251.

EMBRAPA. Empresa Brasileira de Pesquisa Agropecuária. Sistema brasileiro de classificação de solos. 5. ed., revisada e ampliada. Brasília, DF: Embrapa, 2018. 590 p.

FANCELLI, A.L.; DOURADO NETO, D. Produção de milho. Guaíba: Agropecuária, 2000. $360 \mathrm{p}$.

GOMES, L.S.; BRANDÃO, A. M.; BRITO, C.H.; MORAES, D.F.; LOPES, M.T. Resistência ao acamamento de plantas e ao quebramento do colmo em milho tropical. Pesquisa Agropecuária Brasileira, Brasília, v.45, n.2, p.140-145, 2010. https://dx.doi.org/10.1590/ S0100-204X2010000200004. 
LOPES, S.J.; DAL'COLLÚCIO, A.; STORCK, L.; DAMO, H.P.; BRUM, B.; SANTOS, V.J. Relações de causa e efeito em espigas de milho relacionadas aos tipos de híbridos. Revista Ciência Rural, v.37, n.6, p.1536-1542, 2007. https:/ /dx.doi.org/10.1590/S0103-84782007000600005.

PATERNIANI, E.; NASS, L.L.; SANTOS, M.X. O valor dos recursos genéticos de milho para o Brasil. In: UDRY, C.V.; DUARTE, W. Uma história brasileira do milho: o valor dos recursos genéticos. Brasília: Paralelo 15, 2000.p.11-41.

PEREIRA, V.R.F.; CHIODEROLI, C.A.; NASCIMENTO, E.M.S.; SANTOS, P.R. A.; ALBIERO, D.; SILVA, A.O.; SILVEIRA, W.M. Critical variables for estimating productivity in maize as a function of plant population and spacing. African Journal of Agricultural Research, v.13, n.35, p.1828-1836, 2018.

REIS, S.L. Desenvolvimento de genótipos de milho doce: avaliação de genitores e híbridos. Tese (Doutorado em Genética e Melhoramento de Plantas). Campo dos Goytacazes, RJ: UENF, 2009. $76 \mathrm{p}$.

ROSSET, S.J.; RAMPIN, L.; ECCO, M.; LANA, C.M.; SARTO, M.V.M.; KUHN, J.O.

Comportamento de híbridos de milho segunda safra quanto à incidência de podridões na Região Oeste do Paraná. Scientia Agropecuaria, v.4, n.3, p.219-228, 2013.
SANGOI, L.; ENDER, M.; GUIDOLIN, A.F.; BOGO, A.; KOTHE, D.M. Incidência e severidade de doenças de quatro híbridos de milho cultivados em diferentes densidades de planta. Revista Ciência Rural, Santa Maria, v.30, n.1, p.17-21, 2000. https://dx.doi.org/10.1590/S010384782000000100003 .

SANTOS, C.S. Características nutricionais e físicas do milho com diferentes texturas e tempos de armazenamento. Tese (Doutorado em Ciência Animal). Escola de Veterinária e Zootecnia, Goiânia: UFG, 2015. 115p.

SILVEIRA, D.C; BONETTI, L.P.; TRAGNAGO, J.L.; NETO, N.; MONTEIRO, V. Caracterização agromofologica de variedades de milho crioulo (Zea mays 1.) Na região noroeste do Rio Grande do Sul. Revista Ciência e Tecnologia, v.1, n.1, p.01-11, 2015a.

SILVEIRA, D. C.; BONETTI, L. P.; TRAGNAGO, J. L.; NETO, N. Produtividade e características de variedades de milho crioulo cultivadas na região noroeste do rio grande do sul. Agrarian Academy, v.2, n.4, p.60-69. 2015b. http:// dx.doi.org/10.18677/Agrarian_Academy_018.

TIBÃES, E.S.R. Adubação de cobertura em milho crioulo roxo: nutrição e produtividade.

Monografia (Conclusão de Curso em Agronomia). Diamantina: UFVJM, 2018. 28p.

Recebido para publicação em 11/12/2018 e aprovado em 05/06/2019. 